\title{
A Utilização da Indexação de Vídeos com MPEG-7 e sua Aplicação na Educação
}

\author{
Adriana Dallacosta* \\ Renato Luis de Souza Dutra** \\ Liane Margarida Rockenbach Tarouco ${ }^{* * *}$
}

\begin{abstract}
Resumo:
A utilização de vídeos educacionais no processo de ensino e aprendizagem ganhou importantes recursos com o surgimento de padrões, como o MPEG-7, que auxiliam descrevê-los de forma padronizada, possibilitando a busca e seleção de vídeos ou partes dele. A utilização das descrições MPEG-7, escritas em XML e integradas a um repositório de materiais audiovisuais, possibilitarão aos professores de forma simples e rápida, localizar vídeos educacionais que melhor se encaixe para o apoio em sala de aula. Adicionalmente servirá como ferramenta para que o aluno navegue, de forma hipertextual, nos diversos vídeos armazenados neste repositório.
\end{abstract}

Palavras-Chave: Vídeos educacionais, indexação de vídeos, MPEG-7

\begin{abstract}
:
The use of educational videos on the educational process has been improved with new standards, such as the MPEG-7. This standard helps to describe videos in a organized way allowing the searching and selection of these videos. The MPEG-7 descriptions in XML integrated with a audiovisual repository can help teachers to search educational videos that can be used in the classroom. In addition this tool can allow the hipertextual browse on videos stored in the repository.
\end{abstract}

Keywords: Education videos, video indexing, MPEG-7

\section{Introdução}

Desde o surgimento da televisão, as transmissões de aulas e, posteriormente, os vídeos gravados têm sido meios de apoio importantes no processo de ensino e aprendizagem. A pesquisa de Cinelli (2003) indicou que a aprendizagem com o vídeo como ferramenta didática é considerada pela maioria absoluta dos professores, mais de $90 \%$, como sendo significativa. A vídeo-aula quando bem planejada, consegue fazer com que os alunos participem ativamente, muitas vezes procurando certo conteúdo que os professores tem dificuldade de encontrar devido às diversidades e acessibilidade de fontes de informações em nossa sociedade.

\footnotetext{
* Doutoranda em Informática na Educação PGIE/UFRGS, 1ำTenente QCO de Informática do 1ํ Centro de Telemática de Área - Exército Brasileiro, adrianadalla@uol.com.br

". Doutorando em Informática na Educação PGIE/UFRGS, rdutra@pgie.ufrgs.br

Professora Titular, Doutora em Engenharia Elétrica pela USP, Diretora do CINTED-UFRGS, liane@penta.ufrgs.br 
Cinelli (2003) aponta diversas vantagens para utilização de vídeos educativos e entre elas o fato do utilizador poder manuseá-lo, manipulá-lo como se "folheasse um livro": avanços, recuos, repetições, pausas, todas essas interferências no ritmo e norma habitual de apresentação da mensagem audiovisual que distinguem a televisão do vídeo. Entretanto apesar desta liberdade existem alguns limitantes como a dificuldade de encontrar cenas ou conteúdos em um filme com longa duração. Adicionalmente, professores encontram dificuldades em localizar vídeos adequados ao conteúdo de aula em videotecas com grande acervo.

Mesmo sendo uma ferramenta importante, a utilização de vídeos educacionais muitas vezes está associada a um processo de ensino e aprendizagem mais linear. Isto está em desacordo com a tendência atual, que cada vez mais faz uso de documentos interligados e interconectados que podem ser acessados de múltiplas formas (hipertextos) tais como as páginas HTML na Web.

A facilidade de localização de conteúdos na Web é uma característica importante que aplicada a vídeos educacionais pode agregar diversos novos recursos de sua utilização. Neste sentido, novas tecnologias para a indexação de vídeos através de metadados têm surgido nos últimos anos junto com a evolução dos padrões para a TV digital. Entre estes padrões podemos destacar o MPEG-7, um padrão para a descrição das informações estruturais e semânticas de conteúdos multimídia, que foi desenvolvido pelo MPEG (Moving Pictures Experts Group).

Este artigo visa apresentar o padrão MPEG-7 e suas relações com algumas teorias cognitivas. Para tanto na seção 2 é apresentada a aprendizagem linear e a hipermídia. Na seção 3 são analisados os vídeos na educação. Na seção 4 são descritas as características do MPEG-7 e sua integração com um repositório de materiais educacionais.

\section{Aprendizagem linear e a Hipermídia}

A aprendizagem dirigida que se instalou ao abrigo da instituição escolar fundamentou-se num tipo de autoridade que costura um conhecimento da realidade, confinando as possibilidades de construção cognitiva do sujeito a uma estrutura linear pré-determinada.

A quebra da seqüencialidade linear é interessante, pois se pode fazer uma comparação entre o livro e a Internet. Quando se tem um livro, mesmo sabendo que a teoria de um determinado autor ainda não está acabada, a idéia que temos é que se trata de uma obra já acabada. Temos os conceitos de início, meio e fim, ou introdução, desenvolvimento e conclusão. Já na Internet a mesma obra já não se tem a mesma idéia, pois na mesma, com a velocidade com que as coisas acontecem prevalece a noção do inacabado, pois ao se colocar a mesma teoria do mesmo autor, dar-se-á então o início da interatividade na rede, e o poderá se ter então, não dependerá de uma seqüencialidade linear, dependendo do início, meio e fim (Moreira, 2003).

O pensamento contemporâneo é caracterizado pela admissão da incerteza, do acaso, da indeterminação e pela rejeição dos discursos totalizadores que conferem centralidade e objetividade ao conhecimento. Denota, mais do que uma simples mudança na atitude dos cientistas, a emergência de um novo paradigma, uma transformação na própria natureza do conhecimento científico que traz profundas implicações na composição da vida e da sociabilidade. Considera-se que os modelos 
simplificadores e lineares de conhecimento não são mais capazes de gerar explicações suficientes que abarquem os fenômenos em suas múltiplas dimensões (Morin, 1989, 1991).

Cresce a percepção de que somente modelos de pensamento complexos, que incorporem ao mesmo tempo situações cognitivas programadas - ordenadas e aleatórias - desordenadas e que revalorizem a intuição podem gerar explicações coerentes para fenômenos e situações extremamente mutáveis e indeterminados. Este é um aspecto que expõe flagrantemente a incongruência entre as formas de percepção, de comunicação, de construção de conhecimento e de representação social que se vêm afirmando nas últimas décadas e os ambientes tradicionais de aprendizado, em especial a escola.

Alguns estudos, por outro lado, já esboçam uma tentativa de tratar as transformações contemporâneas não como desviantes ou anômalas, mas dentro da própria lógica e ótica dos meios que as condicionam, que implicam a produção de novas capacidades mentais, cognitivas e afetivas. Segundo Hamilton (1993), toma corpo uma escola de pensamento que sugere uma interposição de configurações (mapas) de conhecimento de processos intelectuais (estrutura cognitiva) e de competência técnica (habilidade na solução de problemas), de forma que a aprendizagem escolar não deve se restringir a uma configuração linear (mapa bidimensional), mas organizada em torno da imagem de um hipertexto aberto, favorecido pelas tecnologias da informação. A metáfora hipertextual refere-se ao conjunto de relações e articulações que se atualizam permanentemente e tem como fonte, além da própria compreensão sobre o sistema nervoso humano, o desenvolvimento dos sistemas de conexões e associações (redes neurais), que já se materializam tecnicamente nas redes e nos circuitos elétricos, nos microcircuitos eletrônicos e nos dispositivos de inteligência artificial. Alves (1995) sugere a necessidade de compreender a forma e a inventividade próprias da introdução das novas tecnologias e das novas concepções de conhecimento na vida cotidiana (e em especial na escola) - que se organizam cada vez mais sob uma estrutura de rede: da construção da idéia de conhecimento em rede será possível "abrir espaço e tempo à compreensão das relações entre conhecimento real, o currículo concreto e as novas tecnologias e novos conhecimentos existentes na sociedade".

Segundo Lévy (1990), a idéia de hipertexto foi enunciada pela primeira vez em 1945, por Vanevar Bush ${ }^{1}$, mediante o artigo “As we May think". Nessa publicação, defendeu que a mente humana não funciona de forma linear como estava organizada a maior parte dos sistemas de indexação e organização de informações da comunidade científica. Mesmo considerando não ser possível apreender todo o processo reticular da inteligência, Bush propôs que seria possível criar um dispositivo inspirado nesse processo de funcionamento do pensamento. Dessa forma, criou o Memex para memorização e seleção por associação. Essas conexões materializadas - ainda não chamadas hipertextuais - constituíam uma espécie de memória auxiliar do cientista.

1 Vanevar Bush foi matemático e físico de renome. Nos anos 30, concebeu uma calculadora analógica ultra-rápida que

foi a precursora da primeira calculadora eletrônica digital- Eniac. 
No início dos anos 60, Theodore Nelson criou o termo hipertexto para expressar a idéia de escrita/leitura não linear em um sistema de Informática. Imaginou o Xanadu, algo como uma imensa rede acessível para milhares de pessoas interagirem, consultarem etc.. Lévy (id., ib.) refere-se ao Xanadu como o horizonte ideal do hipertexto, com a materialização do diálogo incessante e múltiplo da humanidade consigo mesma e com o passado. No entanto, até o momento, ainda não foi possível atingir essa amplitude imaginada por esses pioneiros, seja devido a dificuldades técnicas, seja devido a limitações no plano das concepções de hipertextos com vocação universal.

Os hipertextos atuais, em geral, são compostos por blocos de informações (lexias) e por vínculos eletrônicos, chamados links. Segundo Leão (1999), Barthes utilizou o termo lexias para designar blocos de textos significativos. Esse termo foi retomado por Landow, apud Leão (id.ib) e definido como o ponto onde se está antes de um link (ou um nó). Uma lexia pode ser constituída por textos, imagens, ícones etc.,que consistem, nesse caso, em unidades básicas de informação. As lexias podem variar conforme os programas que as geram. Podemos destacar três variações: 1) relativas aos limites que pode adquirir; 2) relativa à presença ou ausência de diferentes graus de hierarquia e 3) tipos de relacionamentos entre diferentes lexias.

Essas lexias, de acordo com Leão (id., ib.), de alguma forma impõem um tipo de construção textual sintética, em que é possível iniciar a leitura de qualquer ponto do sistema. Assim, o hipertexto caracteriza-se por ser um texto fragmentado (em lexias ou blocos de textos), que passam a ter vida própria ao se libertarem da ordem linear.

No hipertexto, o leitor é também de alguma forma escritor, pois é ele quem vai estabelecer os elos e delinear as trajetórias de navegação. O conceito de texto flexível requer e cria um leitor muito mais ativo. Segundo Quéau, apud Leão (id., ib.), os hipertextos exigem novas formas de "navegação mental" para que seja possível reencontrar-se nos "labirintos informacionais" em constante reconstrução.

Hipermídia, Intranet e/ou Internet é comumente definida como uma forma não linear de armazenamento e recuperação de informações. Isto significa que a informação pode ser examinada em qualquer ordem, através da seleção de tópicos de interesse. Desta forma, estas tecnologias têm como principal característica à capacidade de interligar pedaços de textos ou outros tipos de informação entre si através do uso de palavras-chave ou símbolos.

Tecnicamente, Lévy (1990) descreve um hipertexto como um conjunto de nós conectados por ligações. Os nós podem ser palavras, páginas, imagens, gráficos, sequiências sonoras e, documentos complexos. Os itens de informações não são ligados linearmente, mas através de ligações como estrelas de forma reticular. Funcionalmente, a hipermídia é um ambiente de software para a organização de conhecimentos ou dados, para a aquisição de informações e para a comunicação (Campos et alii, 1996). Para Berk (1991), hiperdocumento é um documento de hipertexto construído em parte pelo autor e em parte pelo leitor.

Campos (1994) define hipermídia como "um estilo de construção de sistemas para a criação, manipulação, apresentação e representação da informação na qual a informação se armazena em uma coleção de nós multimídia e onde os nós se encontram organizados em forma explícita ou implícita em uma ou mais estruturas (habitualmente 
uma rede de nós conectados por links), os usuários podem acessar a informação, navegando através das estruturas disponíveis."

Uma visão de currículo a partir da metáfora de rede hipertextual significa admiti-lo como um conjunto de possibilidades, onde ganha especial importância a potencialidade de vivência de experiências significativas. Nessa perspectiva, cremos que a tarefa do pedagogo (como evoca o próprio termo), é de acompanhar o estudante em seu percurso, propiciando a ele vivências por meio das quais tenha acesso a coisas, lugares e processos, a eventos e arquivos, o que o aproxima do sentido original do termo educar, ex-ducere: conduzir para fora (para fora do caminho traçado de antemão). Um currículo que defina um ambiente escolar complexo, além de estabelecer um espaço vivencial - do qual tanto professores quanto alunos são arquitetos e onde reciprocamente co-ordenam as suas experiências - deve ser também caracteristicamente acentrado: numa lógica de conhecimento em rede, hipertextual, não faz sentido centrá-lo quer em disciplinas, quer no método, ou ainda no professor ou no aluno.

A construção deste tipo de ambiente deve reconhecer o desafio de revalorizar a descoberta, adotando uma atitude heurística, e de explorar as coisas não pela decomposição de seus componentes, mas pelo conjunto de relações que implicam. É preciso também admitir que uma intervenção mediadora, com o objetivo de abrir o mais possível o campo de possibilidades, requer uma avaliação sobre o processo da aprendizagem e não sobre o seu produto.

Lévy (1990) enfatiza que a interação ativa de um indivíduo com a aquisição do saber é pedagogicamente interessante. Com a multimídia interativa, isto é, com a possibilidade de uma dimensão reticular, não linear, há o favorecimento de uma postura exploratória diante do conteúdo a ser assimilado. Desta forma, buscas em redes estariam relacionadas à uma aprendizagem ativa. Neste sentido, Midoro (1993) ressalta que o produto de hipermídia e o processo de desenvolvimento de uma aplicação interessam, ambos, à educação. O produto de hipermída consiste em sistemas que tornam possível a disponibilidade de uma grande quantidade de material de aprendizagem estruturado. Este material é acessível a partir de uma máquina e, navegável através de ligações explícitas. $\mathrm{O}$ material de aprendizagem armazenado no produto de hipermídia envolve comunicação de instruções baseada em diferentes canais (texto, áudio, vídeo, etc...).

Estes conceitos, até pouco tempo atrás, pareciam estar dissociados de conteúdos audivisuais, onde a possibilidade de interação e navegação era bastante restrita. Entretanto os avanços na televisão digital e dos dispositivos multimídia têm levado ao desenvolvimento de padrões que permitem aos vídeos estarem mais próximos no conceito de hipermídia. Os vídeos educacionais vêm ao encontro da hipermídia e da aprendizagem, pois a tecnologia está tornando esse tipo de mídia mais atrativo para o aprendiz, levando o aluno, definitivamente, a abandonar a postura supostamente indesejada de mero espectador.

\section{Vídeo na Educação}

Ao fazer um apanhado das múltiplas soluções encontradas em vários países para viabilizar a educação a distância, Peters (2001) relata o modelo encontrado pelos chineses para educar massivamente a distância, baseado quase que integralmente em vídeo, a tal ponto que a denominação extra-oficial do sistema é "universidade televisiva" (Peters, 2001, p. 327). Esse uso, segundo o próprio autor, seria reprovável 
pela maioria dos pesquisadores ocidentais da área educacional, que veriam na prática uma simples transposição do ensino presencial para o modelo transmitido pela televisão.

Entretanto, há um conjunto de justificativas, no universo da cultura chinesa, capazes de validar esse uso, diz Peters. Uma delas seria a escrita ideográfica dos chineses, que, por não ser fonética, dificulta o debate dos assuntos propostos. A aula transmitida em vídeo, de forma linear, contribui para a compreensão dos temas e inclusive sua apresentação fonética, uma vez que os textos os apresentam de forma abstrata. Outra justificativa seria a importância do papel dos professores para os chineses, bem mais valorizados do que na cultura ocidental. Para vê-los e ouvi-los, os alunos seriam motivados a assistir às aulas em vídeo. A situação relatada por Peters reforça a sugestão dos autores, relacionada à necessidade de respeitar a cultura educacional do aluno, na hora do planejamento da tecnologia educacional. No caso dos vídeos para a Internet, sugere-se que a cultura educacional dos alunos estaria mediada pela expectativa que têm a partir da televisão e do cinema, relacionadas aos padrões de linguagem visual e de composição dos elementos, aos quais estão acostumados.

A tecnologia de vídeo na Web, no entanto, ainda está dando os seus primeiros passos. A qualidade das imagens é ruim, a janela do vídeo é pequena e, na maioria das vezes, devido ao problema das baixas velocidades de conexão, som e imagem não estão bem sincronizados. Ainda assim, as experiências com a utilização de vídeos na Web têm dado bons resultados, com os sites que empregam esta tecnologia recebendo um número cada vez maior de visitantes.

Segundo Ferrés (1996) linguagem audiovisual favorece a percepção acima da reflexão, a sensação sobre o conceito, e por este motivo é natural que tenda a provocar respostas mais emotivas, reduzindo o nível de consciência e a possibilidade de uma reflexão crítica.

Decorrente da oportuna conscientização sobre a necessidade de estimular a ação do aprendiz, ocorrida ao longo das últimas décadas, em praticamente todos os níveis de ensino, o uso de vídeos educacionais tem sido pouco desenvolvido como objeto de pesquisa nas faculdades de comunicação e educação. As potencialidades geradas pelos ambientes virtuais, entretanto, agregaram novas razões aos defensores do uso de vídeos educacionais, sejam eles aulas gravadas ou produções mais elaboradas, as quais podem, hoje, estar associadas em conjuntos que favorecem a interatividade, a integração com bancos de dados e outras fontes de pesquisa e aprofundamento. Versões recentes de softwares de edição de vídeo, como o Adobe Premiere, já permitem ao planejador educacional inserir links dentro das cenas, levando o aluno, definitivamente, a abandonar a postura supostamente indesejada de mero espectador. Sugere-se que os vídeos, assim como todos os outros suportes de mídia educacional, devem ser usados segundo a necessidade e a especificidade de cada conteúdo e de cada conjunto de alunos e, sobretudo, conforme já foi colocado, obedecendo à lógica da percepção dos espectadores e da cultura à qual pertencem. Mas seu uso não deve ser negligenciado, pela sua enorme capacidade de sensibilização e motivação dos alunos (Timm et alii, 2003).

Seguindo a linha do Adobe premiere a tecnologia de indexar vídeos tem sofrido enormes avanços, permitindo novas formas de interação e localização em vídeos e cenas especificas. Neste sentido o VALA (http://www.vala.arizona.edu/) apresenta um ambiente de aprendizagem personalizado para cada aprendiz. Dentre as várias 
ferramentas que ele possui, está o software Virage, um sistema comercial para indexação e recuperação de imagens que registra e analisa gramaticalmente as trilhas de vídeo e áudio, permitindo que as buscas sejam realizadas por palavras-chave. Nesta mesma linha surgiram novos padrões que ajudam neste processo. Um destes padrões que começa a ser adotado é o MPEG-7.

\section{MPEG-7 e sua integração com repositório de objetos educacionais}

O MPEG-7 é um padrão para descrever as características de conteúdos multimídia para que os usuários possam pesquisar e recuperar estes conteúdos de forma similar ao que ocorre nos mecanismos de busca na WWW. Para a criação destas descrições, o MPEG-7 disponibiliza um conjunto de elementos de metadados descritos em XML. Além das descrições textuais em arquivos XML, muitas vezes extensas, o MPEG-7 especifica descrições em formato binário, o BiM, permitindo o streaming e a compressão em até $98 \%$ das descrições.

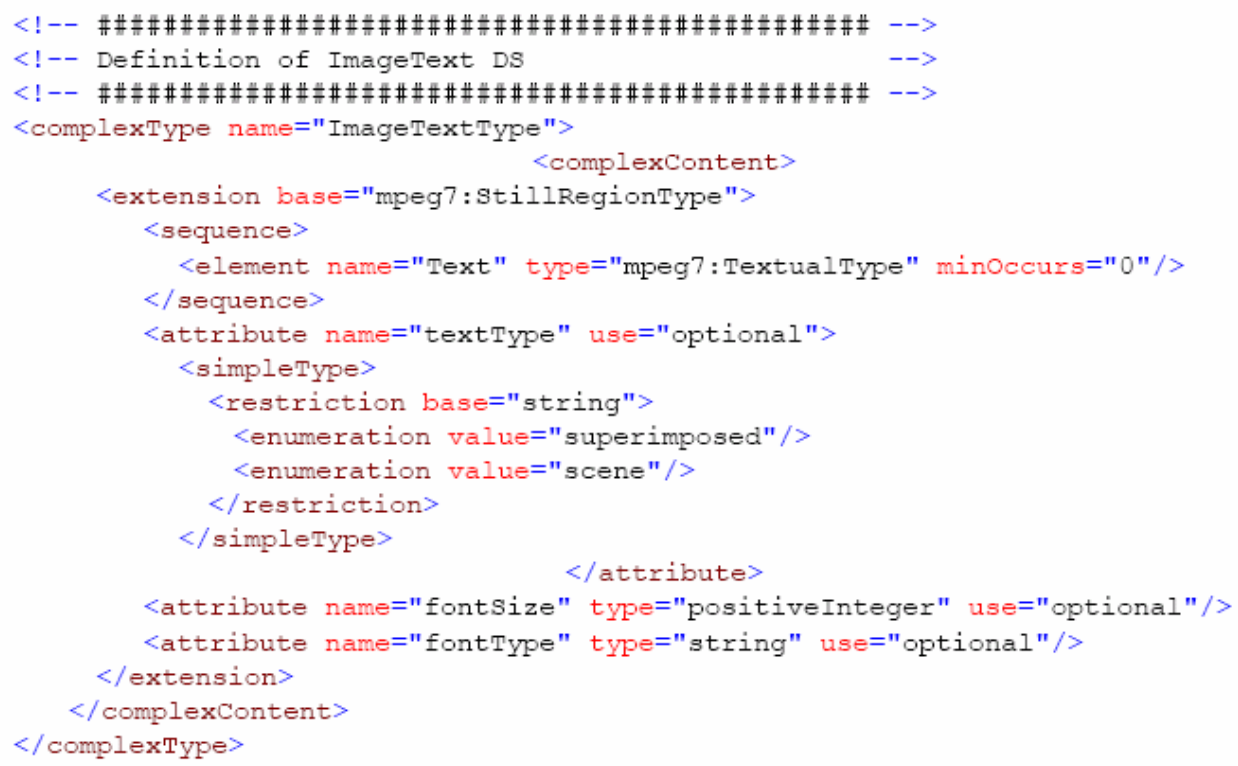

Figura 1 - Exemplo de descrição MPEG-7 em XML

O MPEG-7 pretende disponibilizar ferramentas (nesse caso, as ferramentas são os descritores, que permitem a criação das descrições) para que a busca em imagens, vídeos e arquivos sonoros seja tão fácil quanto é a busca em textos. 


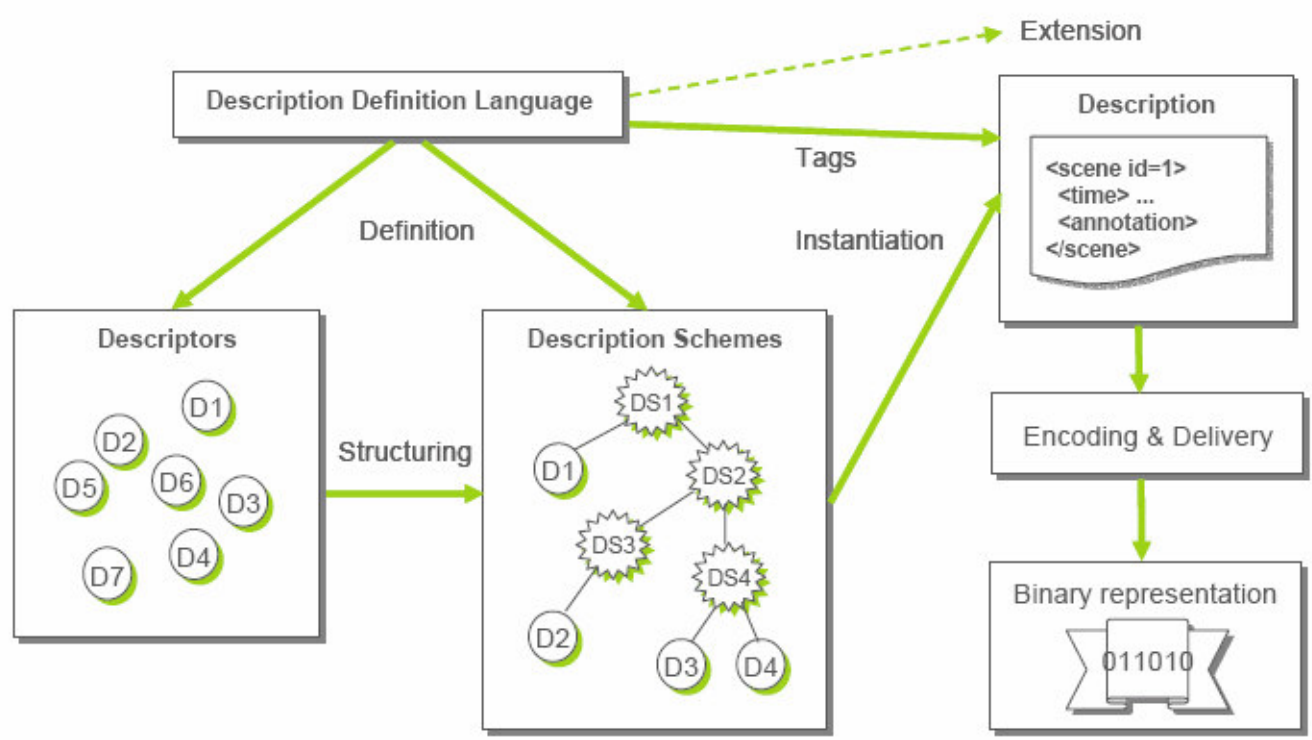

Figura 2 - Elementos principais das descrições MPEG-7

A descrição MPEG-7 pode estar fisicamente armazenada em conjunto com o material audiovisual, como também, pode estar locada em outro lugar através da rede, além de poder ser utilizada independentemente de outros padrões MPEG, tais como o MPEG-2 ou MPEG-4. As principais ferramentas utilizadas para implementar as descrições MPEG-7 são os Descritores, os Esquemas de Descrições e a Linguagem de Definição de Descrições.

Um Descritor define a sintaxe e a semântica de cada característica como, por exemplo, sua cor ou texto do título. O Esquema de Descrição define a estrutura e semântica dos relacionamentos entre seus componentes que podem ser tanto os Descritores como outros Esquemas de Descrição. A Linguagem de Definição de Descrição (DDL) é uma linguagem, definida através de um esquema XML, que permite a criação de novos Esquemas de Descrição e Descritores.

No mercado, já existem ferramentas disponíveis para a indexação e utilização de descrições MPEG-7. Entre as mais conhecidas podemos citar o Ricoh MPEG-7 Movie Tool utilizado para criar descrições, o Canon MPEG-7 Spoken Content Transcription Service um serviço que transcreve em XML no padrão MPEG-7 um arquivo de áudio e o IBM MPEG-7 Annotation Tool.

O IBM Annotation tool é uma ferramenta de uso livre, que auxilia na criação de descrições MPEG-7 para vídeos gravados no formato MPEG-1. Com ele, partes de uma seqüência de vídeo podem ser anotadas através de descrições de cena, descrições de objetos chave, descrições de eventos e outros conjuntos léxicos. As descrições anotadas são associadas com cada parte de vídeo e armazenadas como uma descrição MPEG-7 em um arquivo XML. Com a utilização desta ferramenta o professor pode facilmente criar descrições MPEG-7, que podem ser utilizadas por mecanismos de busca e ferramentas de exibição destes vídeos, assim como ocorre no Projeto VALA.

Nesta linha o CINTED (Centro Interdisciplinar de Novas Tecnologias na Educação) da UFRGS esta desenvolvendo mecanismos de extração de vídeos associados a um repositório de objetos educacionais, o Projeto CESTA.

O projeto CESTA (Coletânea de Entidades de Suporte ao uso de Tecnologia na Aprendizagem) foi idealizado com vistas a sistematizar e organizar a catalogação dos materiais educacionais (objetos educacionais) que vinham sendo desenvolvidos pela 
equipe da Pós-Graduação Informática na Educação e do CINTED, para cursos de capacitação em Gerência de Redes, Videoconferência e na Pós-Graduação Lato-sensu Informática na Educação. Esta catalogação está sendo feita em consonância com normas do padrão IEEE 1484 e os dados de catalogação serão disponibilizados em diretório online usando um servidor LDAP (Lightweight Directory Access Protocol).

A idéia é que o professor possa localizar vídeos educacionais no repositório do CESTA através de palavras-chave. Estas palavras-chave estarão associadas a uma descrição MPEG-7, previamente geradas por um professor, que conterá os segmentos de vídeo que contém aquela palavra-chave, e que possibilitará exibir o filme exatamente nos pontos onde ocorre cada palavra-chave.

$\mathrm{Na}$ fase atual do projeto, o repositório já está totalmente operacional e, através de classes Java já existentes, foi desenvolvida uma ferramenta que permite exibir o filme a partir de uma palavra chave selecionada, utilizando as descrições MPEG-7 geradas pelo IBM Annotation Tool. Entretanto esta ferramenta ainda está em fase experimental e não está totalmente integrada ao repositório do projeto CESTA

\section{Conclusão}

Os vídeos educacionais são importantes materiais de apoio no processo de ensino e aprendizagem. Por outro lado, o surgimento de padrões como o MPEG-7 possibilita expandir as fronteiras destes materiais audiovisuais, tornado-os um material hipermídia, vindo ao encontro com as novas abordagens educacionais que privilegiam formas de ensino não-lineares.

A utilização destas descrições MPEG-7, integradas a um repositório de materiais audiovisuais (objetos de aprendizagem), possibilitarão aos professores, de forma simples e rápida, localizar vídeos educacionais que melhor sirvam para o apoio em sala de aula. Adicionalmente, os alunos, através destas ferramentas, poderão navegar de forma hipertextual nos diversos vídeos armazenados neste repositório.

Espera-se que com estas ferramentas professores e alunos ganhem uma importante ferramenta tanto para a preparação de uma aula como para o uso em pesquisas e atividades em sala de aula. Desta forma, cada vez mais os vídeos passarão a ter uma importante característica de interatividade, além da riqueza visual já existente.

\section{Referências Bibliográficas}

ALVES, Nilda. Encontros. Memorial apresentado à Universidade Federal Fluminense. Niterói: 1995. mimeo.

BERK, E. Text-only hypertexts. Hypermedia Handbook. McGraw-Hill Publishing Co. 1991.

CAMPOS, Fernanda; Campos, Gilda H.B.de \& Rocha, Ana Regina. Dez Etapas para o Desenvolvimento de Software Educacional do Tipo Hipermídia. 3er Congresso Iberoamericano de Informática Educativa. Barranquilla.Colombia. 8-11. Julho. 1996

CAMPOS,Fernanda C.A.; Rocha,A.R.C.da \& Campos, Gilda H.B.de. Hipertexto, Multimídia e Hipermídia: As Fronteiras da Conceituação. Exatas. Revista do I.C.E. Universidade Federal de Juiz de Fora, Juiz de Fora, Vol.1, No.1, pp 25- 40, Mar/Dezembro.1994. 
CINELLI, Nair Pereira Figueiredo. A influência do vídeo no processo de aprendizagem / Nair Pereira Figueiredo Cinelli; orientadora Édis Mafra Lapolli. - Florianópolis, 2003. 72 f. : grafs. , tabs.

FERRÉS, Joan. vídeo e Educação. 2a edição. Porto Alegre: Artes Médicas, 1996

HAMILTON, David. Comênio e a nova ordem mundial. Pro-Posições- Revista da Faculdade de Educação da UNICAMP. Vol4, n.o2[11], julho de 1993. p.7-19.

LEÃO, L. O Labirinto da Hipermídia: Arquitetura e navegação no Ciberespaço. Ed. Iluminuras Ltda. São Paulo, 1999.

LÉVY, Pierre. Les technologies de l’intelligence. Editions La Découverte. 1990.

MIDORO, Vittorio. What makes multimedia systems interesting for education? ED MEDIA 93 - Educational Multimedia and Hypermedia Annual. Proccedings...; AACE. 1993. 377-382.

MOREIRA, Cássio José Motta. COMPUTADOR E EDUCAÇÃO. Disponível em http://www-usr.inf.ufsm.br/ cacau/elc202/Moreira.html, data 23/09/03.

MORIN, Edgar. Introdução ao pensamento complexo. Lisboa: Instituto Piaget, 1991. $145 p$.

PETERS, Otto. Didática do Ensino a Distância. São Leopoldo, Brasil. Ed. Unisinos, 2001.

TIMM, Maria Isabel; Schnaid, Fernando; Zaro, Milton; Ferreira Filho, Raymundo C. M.; Cabral Jr., Paulo Augusto de Freitas; Rosa, Ana Maria. Jesus, Marcelo Azevedo e S. de. Tecnologia educacional: mídias e suas linguagens. Disponível em www.cinted.ufrgs.br/renote/fev2003/artigos/marai_tecnologia.pdf, data 23/09/03. 